\title{
Basaloid squamous cell carcinoma: Report of five cases
}

\author{
Jose-Manuel Morales-Puebla ${ }^{1}$, Mariano Toro-Rojas ${ }^{2}$, Rafael Segura-Saint-Gerons ${ }^{3}$, Josefina Fanego-Fer- \\ nández ${ }^{4}$, Pedro López-Villarejo ${ }^{5}$
}

${ }^{1}$ ENT Department, General Hospital of Ciudad Real, Ciudad Real

${ }^{2}$ Professor of Pathology, Faculty of Medicine, University of Córdoba

${ }^{3}$ Pathology Department, Faculty of Medicine, University of Córdoba

${ }^{4}$ Pathology Department, Reina Sofía Hospital, Córdoba

${ }^{5}$ Head of ENT Department, Reina Sofía Hospital, Córdoba

Correspondence:

Hospital General de Ciudad Real

Servicio de Otorrinolaringología

C/ Pozo Dulce, $19,3^{\circ} \mathrm{E}$

13001, Ciudad Real (Spain)

josemanuelmoralespuebla@hotmail.com

\author{
Morales-Puebla J M, Toro-Rojas M, Segura-Saint-Gerons R, Fanego-Fer- \\ nández J, López-Villarejo P. Basaloid squamous cell carcinoma: Report of \\ five cases. Med Oral Patol Oral Cir Bucal. 2010 May 1;15 (3):e451-5. \\ http://www.medicinaoral.com/medoralfree01/v15i3/medoralv15i3p451.pdf

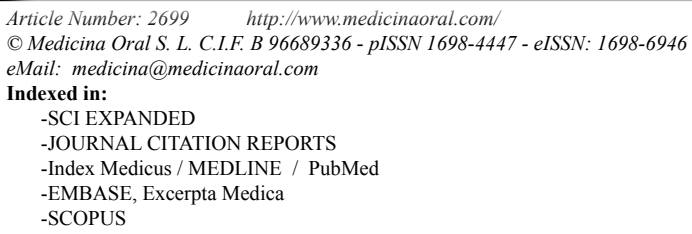

Received: 11/02/2009 Accepted: 28/11/2009

\begin{abstract}
Objectives: To document the clinical and histopathological characteristics of basaloid squamous cell carcinoma (BSCC). To add five new cases to the literature and compare them with another published series.

Cases: retrospective review of five cases with the diagnosis of BSCC of the larynx. Results: all the patients were male. They were heavy smokers and drinkers. Most of the tumours were supraglottic. Three patients presented with stage-IV disease and the other two with stage-I disease. Surgery supplemented with radiation was used in three patients, partial surgery was used in another case and radiation and associated chemotherapy in the other one. Eight neck dissections were performed, six of them were functional and the other two radical dissections. Two cases were found to have metastatic lymph nodes. There were not any distant metastases but two patients had tumoral relapse.

Conclusions: BSCC has well defined histological features. Central comedonecrosis within the cells nests, cell with nuclear palisading and high-grade dysplasia in overlaying mucosa are the main characteristics.
\end{abstract}

Key words: Laryngeal neoplams, basaloid squamous cell carcinoma. 


\section{Introduction}

Basalioid squamous cell carcinoma (BSCC) is a rare variant of squamous cell carcinoma. It was first reported by Wain et al. (1) in 1986. Since then around 200 cases have been published and almost one third of them are located in the larynx (2).

BSCC show the same strong association with tobacco and alcohol as conventional squamous cell carcinoma $(2-4)$. It is mostly seen at the supraglottic larynx, the base of the tongue, pyriform sinus and palatine tonsils. Some cases have been found in the nasopharynx, the floor of the mouth, oral cavity, palate and nasal cavity. Occasional cases have involved the traqueobronchial tree $(2,3,5)$. Histologically identical tumors had been recognized at the anus and esophagus.

This tumor is considered to be very aggressive and it often presents itself as an advanced stage lesion with cervical lymph nodes and distant metastases (5-7). It can be associated with neoplasm in other anatomical sites. In some cases it can be diagnosed as a metastase of an unknown primary carcinoma, in this situation there is high incidence of second primary tumors associated, synchronic and metachronic (8).

For the treatment and prognosis, no systematic studies have been made. If it is possible, patients receive surgical resection, often followed by radiotherapy, chemotherapy or both.

\section{Cases}

Five cases of BSCC are presented. They were diagnosed at the Pathology Department of the University Hospital Reina Sofía, Córdoba (Spain), between 1996 and 2002.

Case 1: A 62-year-old male, smoker 40 cigarettes/day, alcohol drinker $100 \mathrm{~g} /$ day, was evaluated at the ENT (Ear, Nose and Throat) outpatients department for 3-4 month-history of hoarseness and odynophagia. Indirect laryngoscopy: ulceroexophytic mass involving laryngeal face of epiglottis, right false vocal fold and right vocal fold; the right hemilarynx was fixed. There was a palpable lymph node in the right side of the neck. Computed Tomography (CT) of the neck: neoformation in right hemilarynx that invades and destroys the homolateral thyroid cartilage, right lymph nodes. Clinical stage: T4N2M0. The patient underwent total laryngectomy and bilateral, functional neck dissections in May 1996. Pathologist report: BSCC and metastatic lymph nodes in right neck dissection. One year after the patient presented tumor relapse in the central area of the neck treated with four cycles of chemotherapy and surgery to remove the tumor. The treatment was completed with radiotherapy. In February of 1999 a new tumor was diagnosed in the floor of the mouth treated with submaxilar dissection. In July of the same year a new mass was detected under the jaw and it was also removed. The Pathologist informed as undifferentiated squamous cell carcinoma, basaloid type. In September of 2000 the patient needed surgery once again because of a new locoregional recidiva concerning the jaw and the tongue. He died in March of 2001.

Case 2: A 51-year-old male, smoker at least 40 cigarettes/day, alcohol drinker 100-150 g/day was referred to the ENT outpatients department for evaluation of a 3 months history of hoarseness without any other symptoms. Endoscopic examination: erythroplasic diffuse lesion involving the left vocal fold without affecting its mobility. Clinical stage: T1N0M0. Biopsy: BSCC. In December 1996 the patient underwent a frontolateral laryngectomy. Histopathologycal study showed negative surgical margins. During the follow-up a new tumor was detected in the left side of the basis of the tongue and once histologycally confirmed (BSCC) the patient underwent a total laryngectomy extended up to the base of the tongue, left radical neck dissection and right functional neck dissection in March 1998. Treatment was completed with radiotherapy. The patient died due to deterioration of health without tumor disease in February 2001.

Case 3: A 68-year-old male, smoker 40-60 cigarettes/ day and alcohol drinker $>80 \mathrm{~g} /$ day. He was evaluated in the outpatients ENT department with a history of some months progressive hoarseness. Indirect laryngoscopy: supraglottic mass involving the epiglottis pharingoepiglottic folds and vallecula, vocal folds were mobile. CT scan: supraglottic mass with right lymph nodes. Clinical stage: T2N2M0. In September 2000 the patient underwent supraglottic laryngectomy, modified right radical neck dissection (spinal nerve preserved) and left functional neck dissection. Pathologist's report: BSCC of the larynx with metastatic lymph nodes in the right neck dissection. 2 months later the patient underwent total laryngectomy because of pneumonia as a consequence of insufficient glottis closure. The last follow up in January 2006 without tumor disease.

Case 4: A 63-year-old male, smoker 40-60 cigarettes/ day, regular drinker was referred to the ENT department for evaluation of a 6-7 months history of odynophagia. Indirect laryngoscopy: swollen epiglottis. There were not any palpable lymph nodes in the neck. Clinical stage: T1N0M0. The biopsy of this lesion was informed as poorly differentiated squamous cell carcinoma. The patient underwent supraglottic laryngectomy in March 2002 and bilateral functional neck dissection. The surgical piece was reported as poorly differentiated squamous cell carcinoma, basaloid type, without tumor in the lymph nodes. During the follow-up there was not tumor relapse but at the beginning of March 2006 he was diagnosed with an acute myeloid leukemia that caused his death at the end of this month.

Case 5: A.F.G. A 49-year-old male, smoker 40 cigarettes/day and alcohol drinker 80-100 g/day was evalu- 
ated at the ENT outpatients department for a 3-month history of odynophagia and dysphagia without dyspnea or hoarseness. Indirect laryngoscopy: mass involving the right lateral wall of the pharynx, right pyriform sinus and epiglottis. The left endolarynx was healthy and the vocal fold mobile. There were no palpable lymph nodes in the neck. The biopsy was reported as poorly differentiated squamous cell carcinoma, basaloid type. CT scan: big mass involving the right piriform sinus, ariepiglottic fold, epiglottis and right preepiglottic space. Clinical stage: T4N2M0. It was decided to make treatment with chemo and radiotherapy (May 2002) with apparent remission of the illness. In August 2005 the patient was admitted to Hospital with progressive dysphagia because of tumor relapse in the esophagus. In September of this year second line chemotherapy was tried but in October the patient died.

\section{Pathological Study}

Microscopically, the tumors consisted of cords and nests (Fig. 1) of basaloid cells. Larger nests frequently exhibit central comedonecrosis (Fig. 2 and 3). Cells at the edge of the nests show nuclear palisading. It has the same low-power microscopic appearance of adenoid cystic carcinoma due to the interspersion of mucinous material or hyalinized stroma conforming sometimes a cribiform-like pattern within the cell nests (Fig. 2). It is also possible to see smaller gland-like spaces filled with mucin or hyalinized material. The basaloid cells have a high nuclear to cytoplasmic ratio, often with dense, hyperchromatic nuclei. Sometimes, nuclei may appear more vesicular with scattered nucleoli. There are lots of mitotic figures and atypical forms can be easily found. Foci of squamous differentiation are always present consisting of cells with plentiful eosinophilic cytoplasm, intercellular bridges or keratin pearl formation. There is

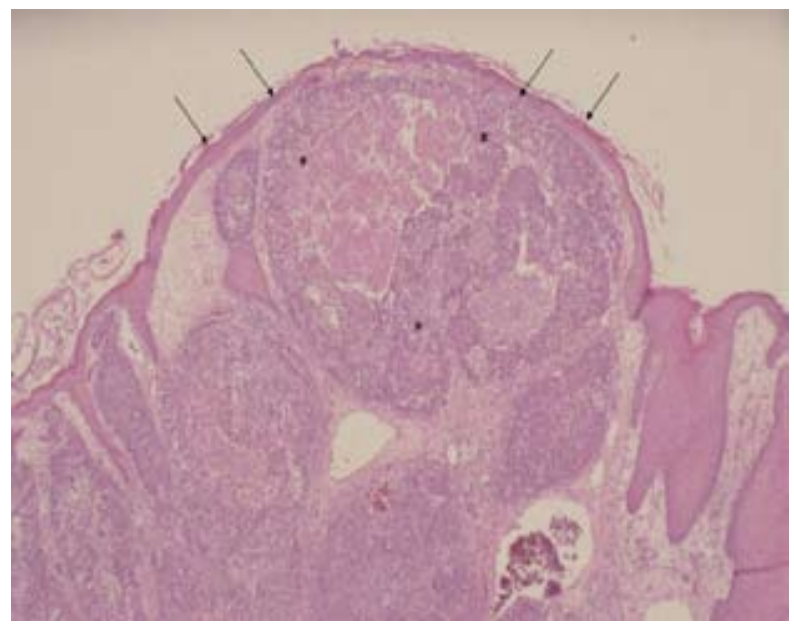

Fig. 1. Case $n^{0}$ 4: panoramic vision of the tumor (asterisks) respecting the overlying epithelium (arrows). H.E. 40x.

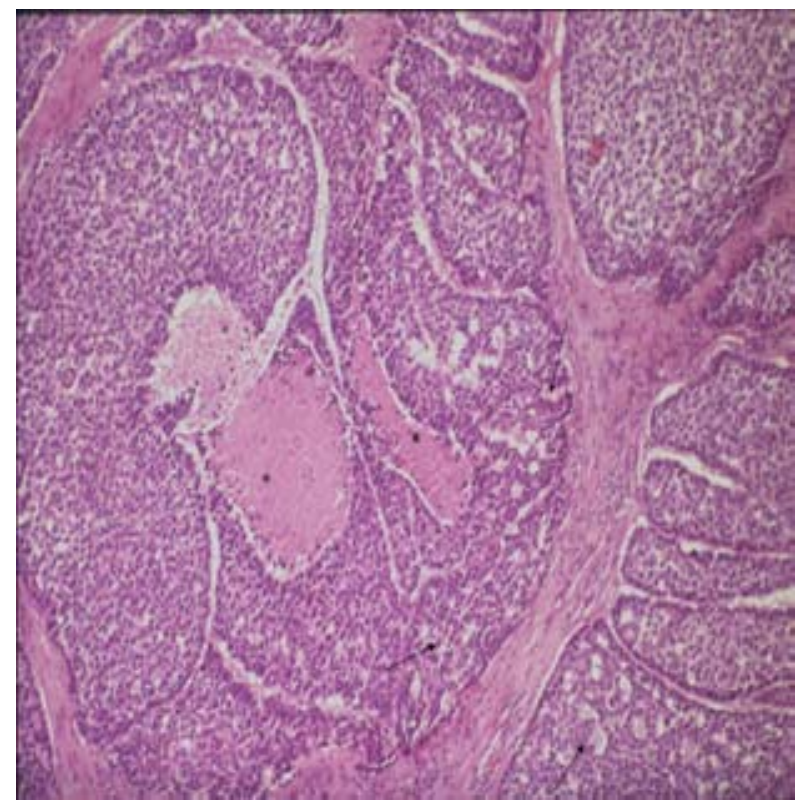

Fig. 2. Case $n^{0}$ 2: there are two areas of comedonecrosis (asterisks) inside the tumor and also crybiform pattern areas (arrows). H.E. $100 x$.

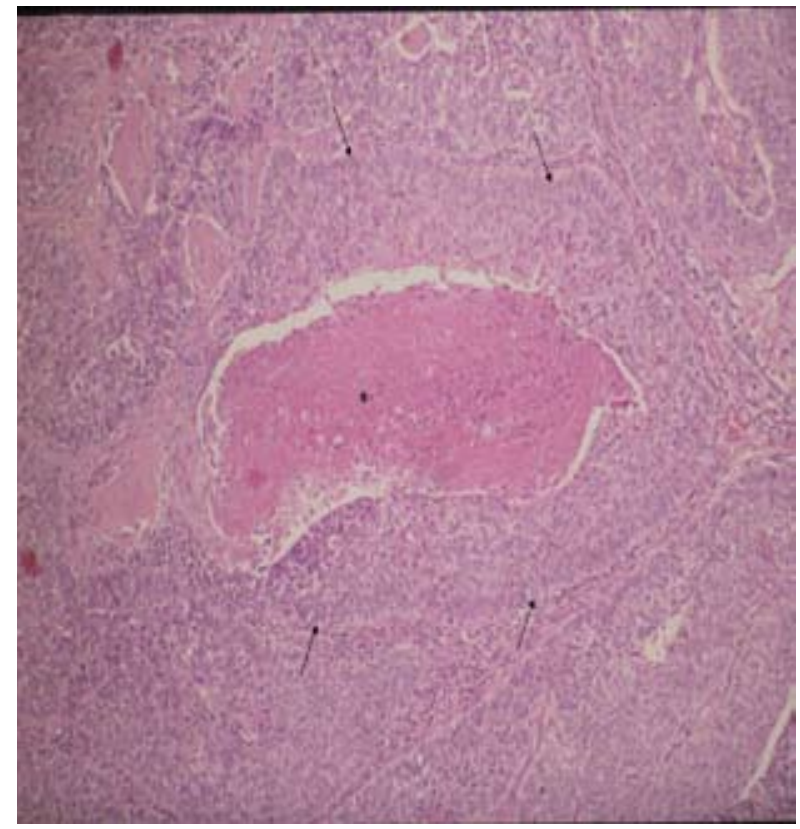

Fig. 3. Case $n^{\circ} 4$ : comedonecrosis area (asterisk) with peripheral palisading (arrows). H.E. 100x

no transitional area between the squamous differentiated and the basaloid differentiated cells. Although large zones of conventional squamous cell carcinoma may be found outside, but adjacent to, the basaloid component, our five cases were mainly basaloid ones.

In the intact surface mucosa overlying a basaloid squamous cell carcinoma high grade dysplasia is usually 
seen. Perineural invasion and lymphatic/vascular invasion were observed in some cases.

\section{Dicussion}

BSCC makes up less than $1 \%$ of laryngeal carcinoma. The pathological features of this squamous cell subtype carcinoma and its non-specific macroscopic aspect makes its diagnosis difficult for the clinician and the pathologist $(4,9,10)$. But microscopic examination reveals distinct and specific features that define these tumors. The intact overlying mucosa with high-grade dysplasia, the plentiful number of mitosis, the nuclear pleomorphism and areas of comedonecrosis distinguish them from adenoid cystic carcinoma. Stromal mucinousmyxoid changes, hyalinosis, the extended squamous differentiated areas and the dysplasia of the overlying mucosa permit us to differentiate basaloid carcinoma from small cell undifferentiated carcinoma $(6,10)$.

As in the majority of the published series, our cases present in males, between the sixth and the seventh decade of life, with a history of smoking and alcohol (3-7). Authors such as Alkan et al and Coppola et al. have published series with earlier ages $(10,11)$.

The supraglottic predominance of these tumors is also common in our patients $(3,4,6,10)$.

There is no established consensus for treatment. Surgery of the tumor and the lymph nodes associated with radiotherapy is usually seen in most of the literature $(6,7,12,13)$. Some authors defend the utility of chemotherapy because of the high incidence of distant metastasis and the tendency to develop second primary tumors $(6,13)$. Surgery and radiotherapy associated were used in three cases in our series. One of the two remaining cases underwent only surgery due to their initial stage without lymph node affectation. In the last case the stage of the disease was so advanced at the diagnosis that the elected treatment was chemotherapy and radiotherapy associated.

Exist some disagreements concerning to the prognosis. At the beginning it was thought to be worse than classic squamous cell carcinoma, with high incidence of regional and distant metastasis (lung, liver, bone, brain and skin) in early stages $(1,5-7,13)$. Ferlito et al. have the biggest published series of BSCC. In their study the 5 year survival is estimated to be $17,5 \%$ and metastases (regional and/or distant) were found in $86,67 \%$ of their cases (6). Others studies, that present cases diagnosed in an early stage of the disease, show similar prognosis to the classic squamous cell carcinoma $(3,5,10,14)$. However, due to their presentation in advanced stages the global prognosis of this type of tumor tends to be poorer. It is important to emphasize aggressiveness of cases 1 and 5. Both cases were diagnosed in stage IV and they had local relapse 4 and 1 times respectively until the death of the patients. In our series the global
5 -year survival was $20 \%$. Only one of the five patients is still alive with no tumor disease. But if causes of death are analyzed, only in two cases was the tumor the responsible.

The predominant supraglottic location of these tumors can delay the diagnosis. It must pass some time for the tumor to affect the vocal folds and produce hoarseness. The pharyngeal paresthesia produced by the alcohol and tobacco consumption can mask initial pain. All this adds to the aggressiveness of the tumor and time until the patient is evaluated by a doctor can justify the advanced stages at diagnosis.

In the light of these results our data are concordant with that from the authors who postulate a similar prognosis as the classical squamous cell carcinoma; in our series here was not any distant metastasis and lymph node metastasis were found only in two neck dissections.

As the data were taken from the clinical records and their correspondent pathological report there was no need to make differential diagnose with other tumors described in literature (adenoid cystic carcinoma, small cell undifferentiated carcinoma, adenosquamous carcinoma...) $(6,10)$.

\section{Conclusions}

- BSCC has clear histological features that can be diagnosed with hematoxylin-eosin stained sections.

- It is more frequent in males and it has supraglottic predominance.

- It can be infradiagnosed because of the low grade of suspicion from the clinician and the pathologist.

- It is an histologycally aggressive tumor with a high mitotic index.

- When it is diagnosed at an early stage, partial surgery can be used.

\section{References}

1. Wain SL, Kier R, Vollmer RT, Bossen EH. Basaloid-squamous carcinoma of the tongue, hypopharynx, and larynx: report of 10 cases. Hum Pathol. 1986;17:1158-66.

2. Bahar G, Feinmesser R, Popovtzer A, Ulanovsky D, Nageris B, Marshak G, et al. Basaloid squamous carcinoma of the larynx. Am J Otolaryngol. 2003;24:204-8.

3. Bracero F, Gámiz MJ, Soldado L, Conde JM, Redondo M, González MA, et al. [Hypopharynx and larynx basaloid squamous carcinoma: our experience with 6 cases]. Acta Otorrinolaringol Esp. 2001;52:229-36.

4. Eryilmaz A, Gocer C, Acar A, Dagli M, Albayrak L. Basaloid squamous cell carcinoma of the larynx. J Laryngol Otol. 2002;116:52-3.

5. Banks ER, Frierson HF Jr, Mills SE, George E, Zarbo RJ, Swanson PE. Basaloid squamous cell carcinoma of the head and neck. A clinicopathologic and immunohistochemical study of 40 cases. Am J Surg Pathol. 1992;16:939-46.

6. Ferlito A, Altavilla G, Rinaldo A, Doglioni C. Basaloid squamous cell carcinoma of the larynx and hypopharynx. Ann Otol Rhinol Laryngol. 1997;106:1024-35.

7. Paulino AF, Singh B, Shah JP, Huvos AG. Basaloid squamous cell carcinoma of the head and neck. Laryngoscope. 2000;110:1479-82.

8. Seidman JD, Berman JJ, Yost BA, Iseri OA. Basaloid squamous 
carcinoma of the hypopharynx and larynx associated with second primary tumors. Cancer. 1991;68:1545-9.

9. Santamaría Mifsut R, Sánchez González F, Limón M, Caballero Villena I, Pérez Sánchez J, Paulino Herrera J, et al. [Basaloid squamous cell carcinoma of the larynx: report of a new case]. Acta Otorrinolaringol Esp. 1996;47:243-5.

10. Alkan S, Coskun BU, Ugur S, Başak T, Dadas B. Basaloid squamous cell carcinoma of the larynx. Auris Nasus Larynx. 2006;33:71-4.

11. Coppola D, Catalano E, Tang CK, Elfenbein IB, Harwick R, Mohr R. Basaloid squamous cell carcinoma of floor of mouth. Cancer. $1993 ; 72: 2299-305$.

12. Larner JM, Malcolm RH, Mills SE, Frierson HF Jr, Banks ER, Levine PA. Radiotherapy for basaloid squamous cell carcinoma of the head and neck. Head Neck. 1993;15:249-52.

13. Erdamar B, Suoglu Y, Sirin M, Karatay C, Katircioglu S, Kiyak E. Basaloid squamous cell carcinoma of the supraglottic larynx. Eur Arch Otorhinolaryngol. 2000;257:154-7.

14. Erisen LM, Coskun H, Ozuysal S, Basut O, Onart S, Hizalan I, et al. Basaloid squamous cell carcinoma of the larynx: a report of four new cases. Laryngoscope. 2004;114:1179-83. 